\title{
Ethnic Identity and Acculturation Orientation of Chinese Yi Villagers in the Context of Social Media
}

\author{
Yuan Shuangyun and Li Hongxia ${ }^{1}$ \\ Rajamangala University of Technology Rattanakosin, Thailand
}

\begin{abstract}
In the information age, the widespread application of social media will impact the ethnic identity and acculturation of ethnic minority individuals. In this study, $522 \mathrm{Yi}$ people from different Yi branches were selected to investigate the relationship between their ethnic identity and acculturation orientation and the role of social media and social support. The results showed that :(1) the acculturation patterns of Yi villagers were mainly integrated, and experienced from separation to integration, then assimilation and marginalization after mixed; (2) The individual differences of acculturation orientation were significant, but the individual differences of ethnic identity were not; (3) Ethnic identity had a positive impact on original acculturation attitude but had no significant effect on mainstream acculturation attitude; (4) Social media had a negative predictive effect on the original acculturation attitude, a positive predictive effect on the mainstream acculturation attitude, and a negative moderating effect on the relationship between ethnic identity and original acculturation attitude; (5) Social support has a positive predictive effect on both acculturation attitudes. Therefore, the government and relevant departments should strengthen social media's popularization in pure Yi areas, enhance social support in mixed areas, and improve education and economic development to improve the acculturation of the $\mathrm{Yi}$ villagers effectively.
\end{abstract}

Keywords: acculturation, ethnic identity, social media, social support, Yi villager.

The rapid development of the information age has brought about a series of social changes, among which the wide use of social media has a profound impact on people's life and cognitive mode (Miller, 2015). In China, social media platforms like WeChat and Tik Tok have been widely popularized nationwide and penetrated the lives of ethnic minorities. Social media use influences people's establishment and maintenance of social network relationships and provide them with opportunities and platforms to understand and learn about different cultures (Zhao Dan, 2018). Some scholars have pointed out that social media can affect acculturation and ethnic identity (Li \& Tsai, 2015; Mitra \& Evansluong, 2019). However, few scholars have empirically tested the different effects of social media on acculturation and ethnic identity.

China is a multi-ethnic country, where the mainstream culture (Han culture) and the non-mainstream culture (minority culture) coexist. Ethnic minority residents often appear as culturally disadvantaged groups in cross-cultural contact. When the original culture collides with the powerful mainstream culture, they will generally face acculturation (Liu Ting, 2020). Among the numerous studies on the acculturation of ethnic minorities, there is almost no study on acculturation of the Yi adult villagers. The Yi ethnic is an ancient ethnic group in China.

${ }^{1}$ Corresponding Author E-Mail: lihongxia@ctbu.edu.cn 
The long historical changes in the past still retain its unique traditional culture and religious belief. However, with the shift in the information age, the traditional Yi villagers are not adapted to the mainstream people in contact. The main manifestations are: (1) the separation between the Yi villagers and the mainstream group; (2) the opposition and contradiction between the Yi group and the mainstream group; (3) the disappearance of traditional Yi culture. Therefore, the study of Yi villagers' acculturation contributes to the stability and unity of the Yi region, the inheritance, and the development of Yi traditional culture, and can provide feasible decisionmaking suggestions for the government and relevant decision-makers.

This study will focus on these questions: how well do the Yi villagers acculturate to modern mainstream society? What are the individual differences in their ethnic identity and attitude towards acculturation? Does ethnic identity positively predict acculturation orientation? Do both social media and social support predict acculturation? The following introduction will elaborate on these questions and the assumptions of this study.

\section{Ethnic Identity and Acculturation}

Ethnic identity and acculturation are two closely related concepts. Phinney et al. (2001) noted that acculturation and ethnic identity are two related processes and should not be studied separately. Acculturation is generally defined as the process in which one cultural group accepts the beliefs and behaviors of another cultural group. It is the acculturation of immigrants to mainstream society (Haugen \& Kunst, 2017). Currently, acculturation is also defined to be a two-dimensional process, in which the changes of the original culture and the mainstream culture occur independently in one direction (Hjellset \& Ihlebek, 2019). Ethnic identity is a component of "consciousness, self-label, attitude and behavior" that leads to an individual's identification with a particular group and emotional attachment to that group (Verkuyten, 2018). Ethnic identity is considered a process of individual identity construction. According to Douglas and Umana-Taylor (2016), identity is a constantly changing process of development. Over time, an individual's understanding of identity goes through a process from exploration to commitment due to a combination of individual experience and actions. Early studies showed that immigrants who adapted to the mainstream culture were more likely to forget the traditions of their original culture (Berry \& Annis, 1974). However, current studies found that the development of a new mainstream cultural identity does not mean that one cannot maintain their ethnic identity (Compton et al., 2018). It indicates that ethnic minority individuals in the mainstream culture are undergoing a complex process of acculturation and identity construction.

While research on acculturation and ethnic identity has increased in recent years, specific studies focusing on how different groups adapt to culture remain contradictory (Mesoudi, 2018). Hsiao \& Wittig (2008) found that the ethnic identity of immigrants of European descent was positively correlated with cultural adaptation. Cavdar et al.'s (2021) research showed that the relationship between ethnic identity and acculturation of secondgeneration Turkish teenagers in Britain is complex and uncertain. Ethnic identity and acculturation have different interactions for different people in different environments. Specifically, acculturation orientation and ethnic identity are influenced by the environment. Current acculturation focuses on the creation of mixed identities, which is particularly prominent in multi-ethnic countries (Groenewold \& de Valk Helga, 2017).

This study holds that ethnic identity is an individual's recognition and commitment to their ethnic and ethnic belonging. It is a kind of value. Such ethnic values are usually formed in the individual's growth stage and are not easily changed in adulthood. Unlike ethnic identity, acculturation changes an individual's orientation and behavior to the new environment. Among them, acculturation orientation to different cultures reflects the process of acculturation. 
Psychological and behavioral changes reflect the results of acculturation. A person's attitude towards acculturation is often changed with the environmental change. That is why acculturation is affected by many factors.

\title{
The Yi Ethnic and the Acculturation Orientation of Yi Villagers
}

The Yi ethnic group is the sixth-largest ethnic minority in China, with a large population and a wide range of branches, mainly distributed in southwest China (in Sichuan, Yunnan, Guizhou, and Guangxi provinces). Yi Autonomous Regions in Sichuan and Yunnan provinces are the main areas where the $\mathrm{Yi}$ people live (the $\mathrm{Yi}$ people in other places are mixed communities). Due to historical changes, the Yi in these two areas had different cultural characteristics and formed the two representative branches of Yi in China: Sichuan Yi and Yunnan Yi. Sichuan Yi people are the most primitive representatives of the Yi ethnic. Due to their closed geographical environment, they had been living in a closed and autonomous slavery society before the 1950s, which is called the living fossil of the slave age (Liu Xing, 2019). The $\mathrm{Yi}$ in Yunnan began to accept the jurisdiction of the central dynasty more than 600 years ago and came into contact with the mainstream Han. Although it is under the jurisdiction of the Han ethnic, it has always been the implementation of the Yi Regional Autonomy policy. Their characteristics are still remarkable. The mixed area's Yi people live in the Han areas and practice the mainstream policy.

With China's rapid economic development, especially poverty alleviation and new rural construction in recent years, and the widespread use of social media, the primitive Yi society is undergoing rapid changes. This study will take Sichuan Yi, Yunnan Yi, and other mixed areas' Yi villagers as the research objects to analyze the ethnic identity and acculturation orientation in these different historical backgrounds and environments.

Acculturation is a two-dimensional process, which includes both the preservation of traditional culture and the acceptance of mainstream society (Berry \& Hou, 2019). A considerable number of studies had shown that Berry's two-dimensional acculturation theory applies to ethnic minorities in China (Zhang Jing-ling \& Zhang Qing-lin, 2007). Therefore, this study assumed that:

\begin{abstract}
H1: the acculturation of the Yi villagers has a two-dimensional structure. They maintain their original cultural identity and cultural characteristics (original acculturation attitude); they hope to establish and maintain a positive and good relationship with members of mainstream society (mainstream acculturation attitude). These two different cultural attitudes can be divided into four different acculturation types: assimilation, integration, separation, and marginalization.
\end{abstract}

\section{Ethnic Identity and Acculturation Orientation of the Yi Villagers}

Previous studies had shown that there was a significant correlation between acculturation orientation and ethnic identity. There is a direct link between acculturation orientation and the development and change of ethnic identity. Those who have achieved an ethnic identity have an attitude that supports cultural preservation, while the negative ethnic identity is often accompanied by a sense of isolation and cultural separation. When members of ethnic minority groups develop a strong sense of belonging to their ethnic community due to the environmental pressure to assimilate national culture, their sense of ethnic identity may be 
substantial (Lardier et al., 2018). When there is hostility towards minorities, exclusion of national culture is more likely (Verkuyten, 2018).

In this study, different from the previous research objects of immigrants and adolescents, the Yi villagers are local adult residents whose ethnic identity may have been formed and relatively stable and may not be easily affected by the attitude of acculturation. On the contrary, the Yi individuals are likely to have different acculturation orientations due to their distinct ethnic identity. Individuals with high ethnic identity are more likely to have a positive original acculturation attitude due to their positive ethnic values. Individuals with low ethnic identity tend to yearn for mainstream society and mainstream culture. Therefore, this study hypothesized that:

\section{H2: ethnic identity positively predicts the original acculturation attitude and negatively predicts the mainstream acculturation attitude.}

\section{Social Media}

Social media refers to a web-based service that allows users to create personal public or semi-public profiles, exchange information, establish connections and socialize with many other users (Ellison et al., 2007). Social media provides users with a platform for communication and sharing. Users communicate by sharing relevant content to carry out real and virtual social interaction (Chung \& Koo, 2015). As a popular platform, social media has become an essential tool for information sharing and relationship building in people's daily life. Social media has become an essential means for them to relieve various kinds of cultural shock and acculturation pressure they suffer in the multicultural environment (Pang \& Wang, 2020; Smith \& Khawaja, 2011). However, scholars have drawn inconsistent conclusions about how social media affects acculturation. Studies have shown that social media provides a platform for ethnic minorities to gather. Ethnic minorities join online ethnic communities and participate in online collective activities to seek a sense of belonging, thus strengthening their ethnic feelings (Zhao Dan, 2018). Studies also showed that ethnic minority individuals who use social media tend to have more mainstream and modern ethnic behaviors (Pan Yu \& Liu Shengzhi, 2019). The rise of social media is changing people's ability to establish and maintain their existing social network relationships, which is conducive to them to maintain communication and contact with members and friends of their ethnic groups, as well as to help them integrate into the multicultural environment and improve their sense of social identity (Kirschner \& Karpinski, 2010; Purgason et al., 2020). Therefore, the use of social media is a multi-faceted phenomenon (Kirschner \& Karpinski, 2010). The different results generated by it may be due to neglecting considering the particular situation of social media use (Argyris \& $\mathrm{Xu}, 2016$ ).

In China, social media platforms have been widely used in Yi society, among which WeChat has become a fundamental tool for people's daily life, work, making friends, and socializing. Individuals living in Yi villages, far from cities, rely on social media platforms to obtain current social information and communicate with mainstream groups. The knowledge acquired through social media may reconstruct the ethnic cognition of the Yi individuals, and the advanced culture and thoughts of the mainstream society may make them aspire to learn from the mainstream culture, thus enhancing the sense of mainstream cultural identity while weakening the cultural identity of the ethnic group. Therefore, this study assumed that:

H3: social media can negatively predict the original acculturation attitude while positively predict the mainstream acculturation attitude. 
The Individual-Environment Matching theory points out that individual performance results from the interaction between the individual and the environment (Gilbreath et al., 2011). Individuals with high ethnic identity tend to actively explore original cultural information and thus have a strong sense of ethnic belonging. Social media may interact with individuals' ethnic identity, and as environmental factors, positively influence individuals' acculturation process. Therefore, this study hypothesized that:

\section{H4: social media plays a moderating role in the relationship between ethnic identity and acculturation orientation.}

\section{Social Support}

Social support includes all kinds of support from all members within and outside the ethnic group. Social support is considered a vital resource to promote adaptation and buffer stress (Bulut \& Gayman, 2020). Social support can help individuals adapt to the environment, provide the information they need, increase their cultural cognition, and promote positive acculturation orientations (Vinokurov et al., 2020). However, such support may also form barriers in an individual's acculturation, making the individual's social network limited to the source cultural group members and alienated from the mainstream group (Ward et al., 2011). It was found that individuals from ethnic minority groups may be inclined to identify psychologically with their ethnic culture when they receive social support from their ethnic group and cultural activities. When individuals receive little or no social support, they will feel more insecure, lonely, and even depressed and helpless (Ai et al., 2014).

Social support will affect individual's acculturation, and this effect will be more prominent in Yi society. Yi society is a traditionally patriarchal society. The concept of family is deeply rooted in individuals' thoughts (a family is usually a village), and the support from within the family is the essential social support that individuals receive. They attach great importance to mutual help and interdependence among family members (Xiao Zilun et al., 2018). In the Yi language, "Human beings live by their relatives, while the Yi people live by their families." The "family" is a support network to cope with the poverty and discrimination they experience. Social support from the family can help Yi people solve various problems in life, reduce the pressure of acculturation, and promote their positive attitude towards acculturation. External social support can also help individuals adapt to the environment and reduce their alienation from the mainstream group. Therefore, this study hypothesized that:

H5: social support positively predicts both the original acculturation attitude and the mainstream acculturation attitude.

\section{Data and Method}

\section{Sample}

This study selected adult villagers of the Yi ethnic (both parents of the Yi ethnic) living in rural Panzhihua as the research object. Located on the border of China's Sichuan and Yunnan provinces, Panzhihua has historically been governed by the two provinces. It was not until the 1960s that Panzhihua City was established by combining parts of the former two provinces with building a new steel city. Therefore, Panzhihua is a typical area where ethnic minorities live in compact communities (ethnic minority residential areas) and mixed communities (mixed with other ethnic groups). The Yi population in the Panzhihua area is about 130,000, accounting for $8.89 \%$ of the city's total population, covering almost all the branches of the Yi ethnic in China, 
and distributed in different district counties. Three types of subjects were selected in this study, including the Yi ethnic group originally belonging to Sichuan and Yunnan Autonomous Regions and the mixed areas' Yi. The Yi people in the mixed areas are immigrants from other places after establishing Panzhihua city. These Yi people have lived with the Han people for a long time, and their cultural characteristics are not prominent. A stratified sampling method was used to distinguish the branch, region, gender, and age features. A total of 650 questionnaires were sent out from 8 representative Yi villages, and 522 valid questionnaires were recovered. The information of the sample was shown in Table 1.

Table 1

Demographic Characteristics of the Sample $(n=522)$

\begin{tabular}{llccllcc}
\hline Scale & \multicolumn{1}{c}{ Item } & N & Rate $\%$ & Scale & Item & N & Rate $\%$ \\
\hline Gender & Male & 227 & 43.5 & Gender & Female & 295 & 56.5 \\
Area & Sichuan Yi & 207 & 39.6 & Marital & Unmarried & 109 & 20.9 \\
& Yunnan Yi & 192 & 36.8 & status & Married & 380 & 72.8 \\
Age & Mixed & 123 & 23.6 & & Divorce & 33 & 6.3 \\
& $18-29$ & 125 & 23.9 & Monthly & $<1000 ¥$ & 87 & 16.7 \\
& $30-39$ & 144 & 27.6 & income & $1000-2000 ¥$ & 95 & 18.2 \\
& $40-49$ & 119 & 22.8 & & $2001-3000 ¥$ & 154 & 29.5 \\
& $\geq 50$ & 134 & 25.7 & & $>3000 ¥$ & 186 & 35.6 \\
Education & Primary & 122 & 23.4 & Work & Farmer & 189 & 36.2 \\
& school & & & & & & \\
& Junior & 120 & 23 & & Self- & 159 & 30.5 \\
& school & & & & employed & & \\
& High school & 149 & 28.5 & & Regular & 98 & 18.7 \\
& University & 131 & 25.1 & & Others & 76 & 14.6 \\
\hline
\end{tabular}

\section{Measurement Procedure}

Before the large-sample test, 60 villagers of the Yi ethnic in Panzhihua were randomly selected for the prediction test. According to the prediction test results, a few questions were modified to form a formal questionnaire. The stratified sampling method was used in the formal test, considering the characteristics of different demographic variables such as region, gender, age, job, and income. The whole trial lasted four months, during which five Yi college students assisted the Yi villagers in answering questionnaires and received the support and cooperation of the local village director. During the annual celebration day, assembly day, and payment day of the Yi ethnic, contact the village director in advance and drive to do the test.

\section{Measurement Scale}

Acculturation Orientation Scale. To measure the attitude of acculturation, scholars used different methods. The most common step is to select some areas related to intercultural relations, such as language use, food preferences, values, identity, and then create four different attitude statements. Another approach is to create two statements for a particular domain, each of which corresponds to two basic dimensions, and create four acculturation orientation variables by crossing these two dimensions (Berry \& Sabatier, 2010). This study used Qiang Acculturation Questionnaire (QAQ) by Li Han et al. (2016) and revised it according to the actual situation of the Yi people. There were 18 questions, including the original acculturation 
attitude (11 questions) and the mainstream acculturation attitude ( 7 questions), and the score was based on the Likert 7-point scale. The questionnaire passed expert evaluation and pilot test. The reliability and validity of the questionnaire were tested by Exploratory Factor Analysis (SPSS) and Confirmatory Factor Analysis (AMOS). The Cronbach's a of original acculturation attitude, mainstream acculturation attitude, and the total questionnaire were $0.903,0.887$, and 0.938 . Factor analysis found that the KMO value is 0.884 . The extraction of two principal components can explain the total variation of $60.742 \%$. The factor loads of all items are greater than 0.6. The two principal components' combined reliability was 0.924 and 0.913 , and the average variance extracted was 0.526 and 0.601 . The values of RMSEA, RFI, NFI, CFI and $\chi^{2} / \mathrm{df}$ were $0.065,0.904,0.926,0.947$ and 3.2. The dimension model of acculturation orientation fits well with the sample data.

Ethnic Identity Scale. A revised Multiracial Identity Measurement Scale (MEIM-R) by Phinney \& Ong (2007) was used, which was based on Phinney's (1992) MEIM scale. The revised scale has good universality and applies to a broader range of ethnic minority groups. The scale has six items, including exploration (3 questions) and commitment (3 questions), and is rated on the 7-point Likert scale ranging from 1 (strongly disagree) to 7 (strongly agree), with four being neutral. The Cronbach's a coefficient of the scale in this study was 0.873 .

Social Media Scale. In this study, the Social Media Usage Scale (revised version) of Ellison et al. (2007) was used to replace Facebook in the original scale with WeChat in the Chinese context. WeChat is the most representative social media platform in China, which has the status and function similar to Facebook. The scale consists of 8 items. Using Exploratory Factor Analysis of SPSS, the Cronbach's a of the scale is 0.93 , and the KMO value is 0.91 , which is suitable for factor analysis. Two factors, attitude, and frequency can be extracted, explaining $69.7 \%$ of the total variation. The factor load of all items is greater than 0.6 , and the revised scale is consistent with the factor composition of the original scale.

Social Support Scale. Zimet's Perceived Social Support Scale (Zimet et al., 1988) was used in this study. This scale has 12 items, divided into three dimensions: family support, friend support, and other support. Each dimension has four items. We used the 7-point scale, the higher the score, the higher the perceived social support level on the corresponding dimension (or overall social support). The Cronbach's a of the scale in this study was 0.948 .

\section{Results and Analysis}

\section{Acculturation Orientation and Demographic Characteristics of Yi Villagers}

According to Berry's Acculturation Model, when people face the identification and adaptation of ethnic culture and mainstream culture, there will be two problems: whether they retain their own culture; whether they are willing to accept and develop their relations with mainstream culture members. Answers to these questions will lead to four modes of acculturation: integration, assimilation, separation, and marginalization. In this study, the median was selected as the intermediate point across dimensions, and the results of the survey confirmed that Berry's Acculturation Model applied to the Yi villagers. Demographic analysis results (Tables 2 and 3) showed that Yi people adopt the integration type, accounting for 75.9\%; The second is the separation type, accounting for 14.9\%; Assimilation and marginalization were the least, accounting for $5.7 \%$ and $3.4 \%$. It showed that most Yi people's acculturation orientation is integration, which is the best acculturation state. However, there are still a large number of people who hold the separation attitude. The demographic variables characteristics of individuals having the separation attitude are as follows: Sichuan Yi, over 30 years old, low educational background, low income, farmers. 
Besides, there are a small number of marginalized people. The characteristics of marginalized people are as follows: male, mixed area, low income. Marginalization is the worst state of acculturation, and the more marginalized attitude of men may be related to men's personality characteristics. Women are usually more willing to talk about their negative emotions than men to relieve pressure effectively. Low-income individuals are also generally more stressed than those with higher incomes.

Table 2

Classification of Acculturation and Demographic Proportion of Yi Villagers (I)

\begin{tabular}{lccccccc}
\hline \multirow{2}{*}{$\begin{array}{l}\text { Acculturation } \\
\text { Strategy }\end{array}$} & \multirow{2}{*}{$\mathrm{N}$} & Rate $\%$ & \multicolumn{2}{c}{ Gender } & \multicolumn{3}{c}{ Area } \\
\cline { 4 - 8 } & & & Male & Female & Sichuan Yi & Yunnan Yi & Mixed \\
\hline Assimilation & 30 & $5.7 \%$ & $3.5 \%$ & $7.5 \%$ & $1 \%$ & $3.1 \%$ & $17.9 \%$ \\
Integration & 396 & $75.9 \%$ & $75.8 \%$ & $75.9 \%$ & $70 \%$ & $82.3 \%$ & $74.8 \%$ \\
Separation & 78 & $14.9 \%$ & $14.5 \%$ & $15.3 \%$ & $27.5 \%$ & $9.9 \%$ & $2.4 \%$ \\
Marginalization & 18 & $3.4 \%$ & $6.2 \%$ & $1.3 \%$ & $1.5 \%$ & $4.7 \%$ & $4.9 \%$ \\
\hline
\end{tabular}

Table 3

Classification of Acculturation and Demographic Proportion of Yi Villagers (II)

\begin{tabular}{lcccccccc}
\hline \multirow{2}{*}{$\begin{array}{l}\text { Acculturation } \\
\text { Strategy }\end{array}$} & \multicolumn{2}{c}{ Monthly income } & \multicolumn{2}{c}{ Age } & \multicolumn{2}{c}{ Education } & \multicolumn{2}{c}{ Work } \\
\cline { 2 - 9 } & $<1000$ & $\geq 1000$ & $<30$ & $\geq 30$ & $\begin{array}{c}\text { Primar } \\
\text { y }\end{array}$ & $\begin{array}{c}\text { Above } \\
\text { Primary }\end{array}$ & Farmer & Others \\
\hline Assimilation & $4.6 \%$ & $6.0 \%$ & $6.4 \%$ & $5.5 \%$ & $2.8 \%$ & $6.8 \%$ & $3.7 \%$ & $6.9 \%$ \\
Integration & $59.8 \%$ & $79.1 \%$ & $80 \%$ & $74.6 \%$ & 69.7 & $80.0 \%$ & $69.3 \%$ & $79.6 \%$ \\
Separation & $26.4 \%$ & $12.6 \%$ & $9.6 \%$ & $16.6 \%$ & $34 \%$ & $10.3 \%$ & $24.3 \%$ & $9.6 \%$ \\
Marginalization & $9.2 \%$ & $2.3 \%$ & $4 \%$ & $3.3 \%$ & $5.5 \%$ & $3.0 \%$ & $2.7 \%$ & $3.9 \%$ \\
\hline
\end{tabular}

From the comparative data of three different Yi areas, the results showed that the Sichuan Yi has the highest proportion of separation and the lowest assimilation and marginalization. The Yunnan Yi has the highest proportion of integration, while the median proportion's assimilation and marginalization. The mixed areas' Yi has the highest ratio of assimilation and marginalization and the lowest proportion of separation.

\section{Differences in Demographic Variables of Acculturation Orientations}

To further verify the relationship between acculturation orientation and demographic variables, this study used the variance analysis (ANOVA) of SPSS. The score of the two acculturation orientation attitudes was taken as the dependent variable; gender, age, area, education, marital status, and income were taken as the independent variables. The results were shown in Table 4.

The variance analysis showed that age, area, education, and work significantly influence the original acculturation attitude. In contrast, gender, area, education, income, work, and marital status substantially influence the mainstream acculturation attitude. In the original acculturation attitude, for the age, $\mathrm{F}=4.445, \mathrm{p}<0.05$, scores of people over 30 years old were significantly higher than those below 30 years old; about the area, $F=64.581, p<0.001$, the score of Sichuan Yi was markedly higher than that of Yunnan Yi and mixed; for the education, $\mathrm{F}=5.283, \mathrm{p}<0.01$, the primary school score was considerably higher than that of high school and university; for the work, $\mathrm{F}=4.517, \mathrm{p}<0.01$, the score of the farmer group was significantly higher than that of the stable job group. 
Table 4

Analysis of Variance of Acculturation Orientation On Demographic Variables $(n=522)$

\begin{tabular}{|c|c|c|c|c|c|c|c|}
\hline \multirow{2}{*}{$\begin{array}{l}\text { Variabl } \\
\text { e }\end{array}$} & \multirow[t]{2}{*}{ Item } & \multicolumn{2}{|c|}{$\mathrm{M} \pm \mathrm{SD}$} & \multirow{2}{*}{$\begin{array}{l}\text { Variabl } \\
\text { e }\end{array}$} & \multirow[t]{2}{*}{ Item } & \multicolumn{2}{|c|}{$\mathrm{M} \pm \mathrm{SD}$} \\
\hline & & $\mathrm{OAA}$ & MAA & & & OAA & MAA \\
\hline \multirow{5}{*}{$\begin{array}{l}\text { Gende } \\
\mathrm{r}\end{array}$} & \multirow{2}{*}{ Male } & $5.31 \pm 1.0$ & $4.78 \pm 1.1$ & \multirow{4}{*}{$\begin{array}{l}\text { Livin } \\
g \text { area }\end{array}$} & \multirow[t]{2}{*}{ Yi area } & $5.71 \pm 0.9$ & 4.6 \\
\hline & & 2 & & & & 0 & 0 \\
\hline & \multirow{2}{*}{ Female } & $5.41 \pm 1.0$ & $5.04 \pm 1.1$ & & \multirow{2}{*}{ Mix area } & $5.10 \pm 1.0$ & $5.13 \pm 1.0$ \\
\hline & & 3 & 9 & & & 4 & 2 \\
\hline & \multicolumn{3}{|c|}{$\mathrm{F}=1.179 \quad \mathrm{~F}=6.59^{*}$} & & \multicolumn{3}{|c|}{$\mathrm{F}=48.604 * * * \mathrm{~F}=21.70^{* * *}$} \\
\hline \multirow[t]{7}{*}{ Area } & Sichuan & $5.79 \pm 0.8$ & $4.77 \pm 1.3$ & \multirow{7}{*}{$\begin{array}{l}\text { Marit } \\
\text { al } \\
\text { Status }\end{array}$} & \multirow{2}{*}{ Unmarried } & $5.18 \pm 0.9$ & $5.18 \pm 1.0$ \\
\hline & Yi & 2 & 3 & & & 1 & 6 \\
\hline & Yunnan & $5.39 \pm 1.0$ & $4.95 \pm 1.0$ & & \multirow{2}{*}{ Married } & $5.42 \pm 1.0$ & $4.90 \pm 1.1$ \\
\hline & Yi & 0 & 1 & & & 5 & 6 \\
\hline & \multirow{2}{*}{ Others } & $4.60 \pm 0.9$ & $5.16 \pm 1.0$ & & \multirow{2}{*}{ Divorce } & $5.32 \pm 1.1$ & $4.44 \pm 1.4$ \\
\hline & & 6 & 8 & & & 5 & 2 \\
\hline & \multicolumn{3}{|c|}{$\mathrm{F}=64.581 * * * \mathrm{~F}=4.219 *$} & & \multicolumn{3}{|c|}{$\mathrm{F}=2.388 \quad \mathrm{~F}=5.641^{* *}$} \\
\hline \multirow[t]{9}{*}{ Age } & \multirow{2}{*}{$18-29$} & $5.15 \pm 0.9$ & $5.09 \pm 0.9$ & \multirow{4}{*}{$\begin{array}{l}\text { Monthl } \\
\text { y } \\
\text { incom } \\
\text { e }\end{array}$} & \multirow{2}{*}{$<1000 ¥$} & $5.41 \pm 1.2$ & $4.30 \pm 1.2$ \\
\hline & & 6 & 9 & & & 3 & 8 \\
\hline & \multirow{2}{*}{$30-39$} & \multirow{2}{*}{$5.6 \pm 0.91$} & $5.00 \pm 1.0$ & & $1000-$ & $5.57 \pm 0.9$ & $5.04 \pm 1.1$ \\
\hline & & & 3 & & $2000 ¥$ & 3 & 6 \\
\hline & \multirow{2}{*}{$40-49$} & $5.32 \pm 1.0$ & $4.88 \pm 1.3$ & & 2001- & $5.35 \pm 0.9$ & $4.91 \pm 1.1$ \\
\hline & & 5 & 1 & & $3000 ¥$ & 1 & 6 \\
\hline & \multirow{2}{*}{$\geq 50$} & $5.35 \pm 1.1$ & $4.73 \pm 1.3$ & & $>3000 ¥$ & $5.24 \pm 1.0$ & $5.18 \pm 1.0$ \\
\hline & & 6 & 1 & & & 6 & 3 \\
\hline & $\mathrm{F}=4.445^{*}$ & $\mathrm{~F}=2.387$ & & & $F=2.169 \quad F$ & $=12.198 * * *$ & \\
\hline Educatio & Primary & $5.64 \pm 1.0$ & $4.33 \pm 1.1$ & Work & Farmer & $5.60 \pm 0.9$ & $4.67 \pm 1.1$ \\
\hline D & & 3 & 6 & & & 4 & 7 \\
\hline & Junior & $5.40 \pm 0.9$ & $4.96 \pm 1.0$ & & Self- & $5.31 \pm 0.8$ & $4.88 \pm 1.1$ \\
\hline & & 4 & 7 & & empl & 9 & 8 \\
\hline & High & $\begin{array}{l}5.30 \pm 0.9 \\
6\end{array}$ & $\begin{array}{l}5.22 \pm 1.1 \\
0\end{array}$ & & Stable job & $\begin{array}{l}5.16 \pm 1.1 \\
9\end{array}$ & $\begin{array}{l}5.37 \pm 1.1 \\
7\end{array}$ \\
\hline & Universit & $5.14 \pm 1.1$ & $5.12 \pm 1.1$ & & & $5.18 \pm 1.1$ & $5.15 \pm 1.1$ \\
\hline & $\mathrm{y}$ & 3 & 7 & & Uthers & 3 & 0 \\
\hline & $\mathrm{F}=5.283^{*}$ & ${ }^{*} \mathrm{~F}=16.08^{* * *}$ & & & $\mathrm{~F}=4.517 *$ & $\mathrm{~F}=7.078 * * *$ & \\
\hline
\end{tabular}

Notes. $*$ represents $\mathrm{p}<0.05, * *$ represents $\mathrm{p}<0.01, * * *$ represents $\mathrm{p}<0.001$, the same as below.

In the mainstream acculturation attitude, for the gender, $F=6.59, p<0.05$, the female's score is significantly higher than male; for the area, $\mathrm{F}=4.219, \mathrm{p}<0.05$, the Sichuan Yi's score was significantly lower than others; for the education, $\mathrm{F}=16.077, \mathrm{p}<0.001$, the education score increases with the increase of educational background, and the primary school score is significantly lower than others; for income, $\mathrm{F}=12.198, \mathrm{p}<0.001$, the score of less than 1000 was significantly lower than other groups; about the work, $F=7.078, p<0$. 001, the stable working group scores were significantly higher than other groups; in the marital status, $\mathrm{F}=5.641, \mathrm{p}<0.01$, the score of the unmarried group was significantly higher than the married and divorced group.

The above analysis showed that acculturation is related to most demographic variables. In this study, variables such as area, education, and job significantly affect the original acculturation and mainstream acculturation attitudes. However, gender, income, and marital status have no significant influence on the original acculturation attitude but substantially 
influence the mainstream acculturation attitude. Age has a considerable effect on the original acculturation attitude but not on the mainstream acculturation attitude.

\section{Ethnic Identity of Yi Villagers}

The results of variance analysis of ethnic identity were shown in Table 5. The mean value of ethnic identity was significantly higher than the median value of four, indicating that the ethnic identity of the Yi villagers was generally high. The relationship between the Yi area and ethnic identity is significant. The ethnic identity of Sichuan Yi is the highest, while the mixed area is the lowest. Ethnic identity has no significant influence on gender, age, income, education, job, and marital status. The results confirmed that the ethnic identity of the Yi villagers is more stable than the acculturation orientation, which does not change with the increase of age, education, and income.

Table 5

Demographic Differences of Ethnic Identity $(N=522)$

\begin{tabular}{lllll}
\hline \multirow{2}{*}{ Ethnic Identity } & \multirow{2}{*}{ Total } & \multicolumn{3}{c}{ Area } \\
\cline { 3 - 5 } & & Sichuan Yi & Yunnan Yi & Mixed \\
\hline Mean & 5.04 & 5.41 & 5.08 & 4.32 \\
SD & 1.14 & 0.96 & 0.97 & 1.33 \\
F & & $41.15^{* * *}$ & & \\
\hline
\end{tabular}

\section{Partial Correlation Analysis}

Partial correlation analysis was carried out in SPSS to explore the correlation between variables. Demographic variables were set as control variables, and two dimensions of acculturation orientation, ethnic identity, social media, and social support were set as related variables. Adding control variables can effectively avoid the influence of demographic variables on other variables. The results (Table 6) showed that the original acculturation attitude was significantly positively correlated with ethnic identity, social support, and social media, and the highest correlation was ethnic identity. The mainstream acculturation attitude was significantly positively correlated with social support and social media.

Table 6

Correlation Analysis of Ethnic Identity, Acculturation Orientation, Social Support, and Social Media $(D f=512)$

\begin{tabular}{lccccccr}
\hline & Mean & SD & EI & OAA & MAA & SS & SM \\
\hline EI & 5.035 & 1.141 & 1.000 & & & & \\
OAA & 5.363 & 1.029 & $.688^{* * *}$ & 1.000 & & & \\
MAA & 4.928 & 1.172 & $.198^{* * *}$ & $.142^{* *}$ & 1.000 & & \\
SS & 5.229 & 1.029 & $.451^{* * *}$ & $.471^{* * *}$ & $.384 * *$ & 1.000 & \\
SM & 4.210 & 1.525 & $.166^{* * *}$ & $.154^{* * *}$ & $.297 * * *$ & $.292^{* * *}$ & 1.00 \\
\hline
\end{tabular}

Note. EI, OAA, MAA, SS, and SM in the table represent ethnic identity, original acculturation attitude, mainstream acculturation attitude, social support, and social media.

\section{Regression Analysis}

The step-step regression analysis method was adopted to analyze ethnic identity, social support, and social media with original and mainstream acculturation attitudes. The results were shown in Table 7 and Table 8. 
The results in Table 7 showed that the factors affecting the original acculturation attitude include ethnic identity, social support, and social media, among which ethnic identity and social support have a positive predictive effect, while social media has a negative predictive effect. The linear regression equation of original acculturation attitude and its influencing factors is as follows: the original acculturation attitude $=0.676 \times$ ethnic identity $+0.151 \times$ social support $0.12 \times$ social media +1.848 . The determination coefficient is 0.556 , indicating that independent variables can explain a $55.6 \%$ deviation in acculturation. After correction, the determination coefficient is 0.553 , which suggests that the equation's goodness of fit is good. The most influential factor in the model is ethnic identity, and social media has a relatively small impact.

Table 7

Stepwise Regression Analysis of Original Acculturation Attitude ( $n=522)$

\begin{tabular}{|c|c|c|c|c|c|c|c|}
\hline \multirow{2}{*}{$\begin{array}{l}\text { Independent } \\
\text { variable }\end{array}$} & \multicolumn{2}{|c|}{ UC } & \multirow{2}{*}{$\begin{array}{c}\text { SC } \\
\text { Beta }\end{array}$} & \multirow{2}{*}{$\mathrm{T}$} & \multirow{2}{*}{$\mathrm{R}$ square } & \multirow{2}{*}{$\begin{array}{c}\text { Adjust } \\
\text { R square }\end{array}$} & \multirow{2}{*}{$\begin{array}{l}\text { Durbin- } \\
\text { Watson }\end{array}$} \\
\hline & B & SE & & & & & \\
\hline (constant) & 1.848 & .178 & & 10.375 & 0.556 & 0.553 & 1.633 \\
\hline EI & .610 & .029 & .676 & $20.848 * * *$ & & & \\
\hline SS & .151 & .034 & .151 & $4.405^{* * *}$ & & & \\
\hline SM & -.081 & .021 & -.120 & $-3.869 * * *$ & & & \\
\hline
\end{tabular}

Note. EI, SS, and SM in the table represent ethnic identity, social support, and social media.

The results in Table 8 showed that social support and social media have a positive predictive effect on the mainstream acculturation attitude. The linear regression equation of the mainstream acculturation attitude and influencing factors is as follows: the mainstream acculturation attitude $=0.309 \times$ social support $+0.295 \times$ social media +2.137 . The coefficient of determination is 0.239 , and the coefficient of determination after correction is 0.236 . The most influential factor in the model is social support, while the influence of ethnic identity is small, which is removed by the regression model.

\section{Table 8}

Stepwise Regression Analysis of the Mainstream Acculturation Attitude ( $n=522)$

\begin{tabular}{|c|c|c|c|c|c|c|c|}
\hline \multirow{2}{*}{$\begin{array}{l}\text { Independent } \\
\text { variable }\end{array}$} & \multicolumn{2}{|c|}{$\mathrm{UC}$} & \multirow{2}{*}{$\frac{\mathrm{SC}}{\text { Beta }}$} & \multirow{2}{*}{$\mathrm{T}$} & \multirow{2}{*}{ R square } & \multirow{2}{*}{$\begin{array}{c}\text { Adjust } \\
\text { R square }\end{array}$} & \multirow{2}{*}{$\begin{array}{l}\text { Durbin- } \\
\text { Watson }\end{array}$} \\
\hline & $\mathrm{B}$ & SE & & & & & \\
\hline (constant) & 2.137 & .239 & & 8.949 & 0.239 & 0.236 & 1.324 \\
\hline SS & .351 & .046 & .309 & $7.664 * * *$ & & & \\
\hline SM & .226 & .031 & .295 & $7.321 * * *$ & & & \\
\hline
\end{tabular}

Note. SS and SM in the table represent social support and social media.

\section{Moderating Effect of Social Media}

Regression analysis showed that ethnic identity and social media have significant predictive effects on the original acculturation attitude. The moderating effect detection method of SPSS was used to verify the moderating impact of social media. After centralizing social media and ethnic identity and multiplying the resulting centralization coefficients, regression analysis was conducted. Data analysis results (Table 9) showed that the product of social media and ethnic identity has a significant effect on the original acculturation attitude $(\beta=-0.039$, $\mathrm{p}<0.05)$. Hypothesis 4 is supported: social media will negatively regulate the relationship between ethnic identity and original acculturation attitude. 
Table 9

Test of the Moderating Effect of Social Media On Ethnic Identity and Original Acculturation Attitude

\begin{tabular}{|c|c|c|c|c|c|c|}
\hline Model & $\mathrm{R}$ square & $\begin{array}{c}\text { Adjust } \\
\text { R square }\end{array}$ & SE & Variable & B & Sig \\
\hline \multirow{3}{*}{1} & \multirow{3}{*}{.539 } & \multirow{3}{*}{.537 } & \multirow{3}{*}{.701} & EI & 0.664 & .000 \\
\hline & & & & SM & -.053 & .010 \\
\hline & & & & EI & 0.673 & .000 \\
\hline 2 & .542 & .540 & .699 & $\begin{array}{l}\text { SM } \\
\text { EI*SM }\end{array}$ & $\begin{array}{l}-0.050 \\
-0.039\end{array}$ & $\begin{array}{l}.013 \\
.049\end{array}$ \\
\hline
\end{tabular}

Note. EI and SM in the table represent ethnic identity and social media.

\section{Figure 1}

Slope Diagram of the Moderating Effect

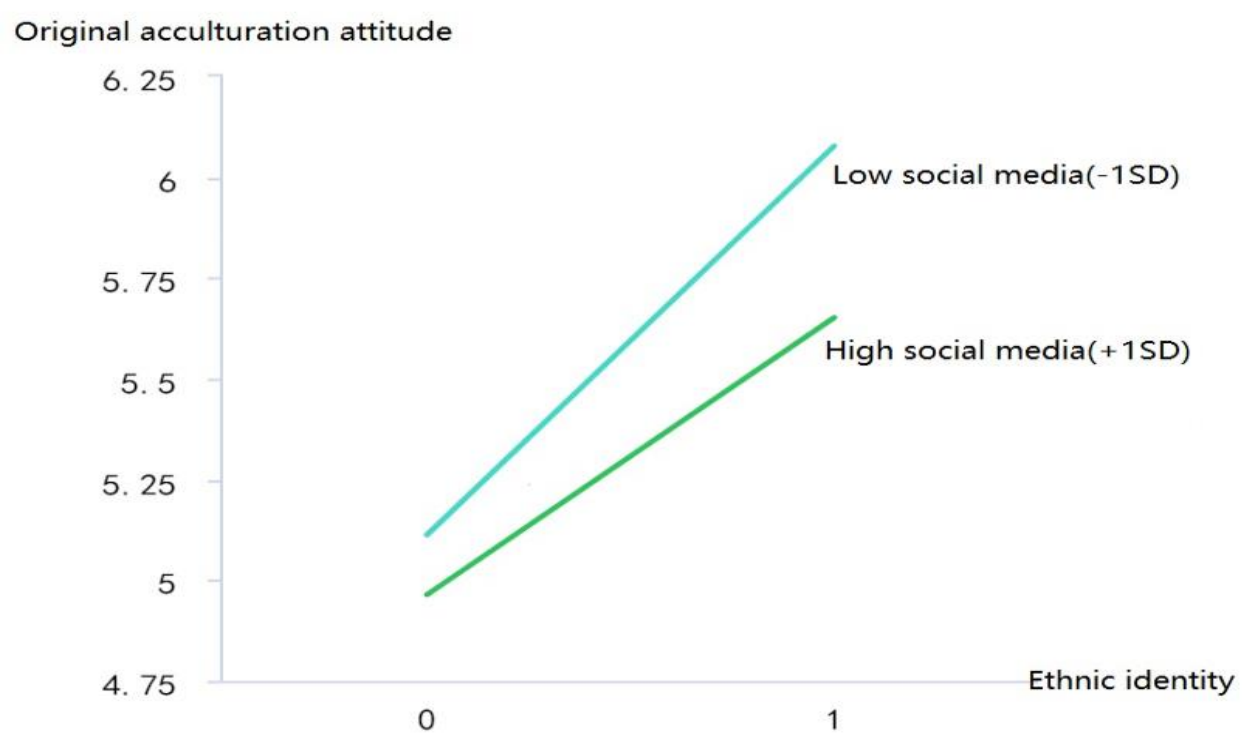

From the above analysis, it can be concluded that the regression equation of moderating effect is as follows: the original acculturation attitude $=5.368+0.673 \times$ ethnic identity $-0.05 \times$ social media $-0.039 \times$ ethnic identity $\times$ social media. According to this equation, we used Excel to draw a simple slope diagram of the moderating effect. Figure 1 clearly shows the different changing trends of ethnic identity and cultural attitudes in high and low social media.

\section{The Model with Moderating Effect}

Based on the above regression analysis and moderating effect analysis results, we drew this study's variable influence effect model (Figure 2). The lines in the model represent the influence relationship, and the values on the lines are the standardized regression coefficient. In the relationship of the original acculturation attitude, EIx SM showed the result of moderating effect. Among the mainstream acculturation attitude influences, the model shows the positive predictive effects of social media and social support. The impact of ethnic identity on the mainstream acculturation attitude is not significant. 
Figure 2

Model Diagram with Moderating Effect

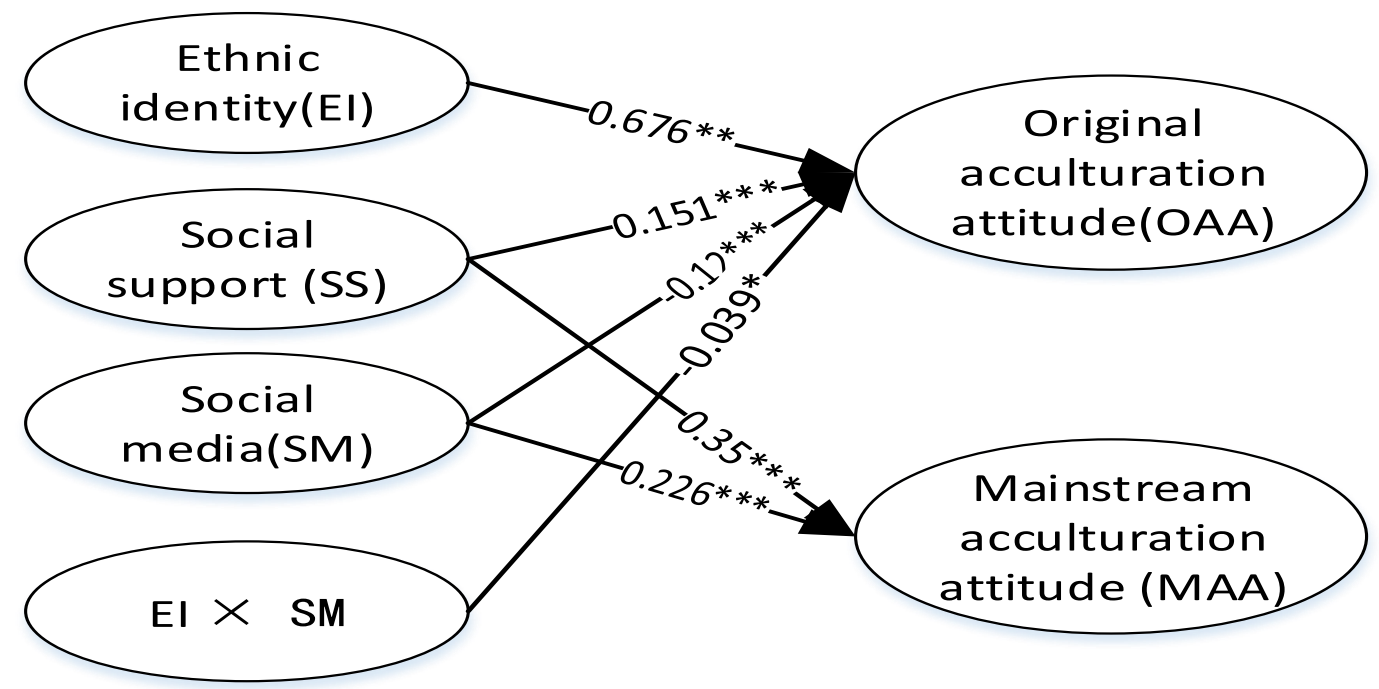

\section{Discussion and Suggestions}

\section{The Acculturation Strategy of Yi Villagers Is Mainly Integrated and Presents Trends of Separation and Marginalization}

According to Berry's Acculturation Model, the acculturation strategies of most Yi villagers are integrated. Integrative acculturation refers to an individual's merging and transcending two cultures, which Berry believed to be the ideal acculturation type. It is also consistent with the acculturation research results of other ethnic minorities in China, indicating that China's mainstream cultural groups have a high degree of acceptance and respect for ethnic minority cultures. However, unlike other ethnic minorities, the proportion of the Yi villagers separated and marginalized is also relatively high and shows significant differences among different branches and regions. The Sichuan Yi had the highest proportion of separation, the Yunnan Yi had the highest proportion of integration, and the other mixed had the highest proportion of assimilation and marginalization. In the development process of Yi people represented by different branches from primitive to modern society, their acculturation orientation also experienced assimilation and marginalization from separation to integration. In the development process of $\mathrm{Yi}$ people represented by different branches from primitive to modern society, their acculturation orientation also experienced from separation to integration, then assimilation and marginalization after mixed.

\section{Individual Differences in Acculturation Are Significant, While Individual Differences in Ethnic Identity Are Not}

The results showed that acculturation presents distinct individual differences. An Individual's age, gender, education, income, job, and marital status significantly affect their acculturation orientation. The age difference in acculturation showed that the older Yi villagers were conservative, and they were more inclined to their own culture; the younger Yi villagers are more open to mainstream culture. The more marginalized attitude of men may be related to the personality characteristics of men. Women are usually more willing to talk about their negative emotions than men to relieve pressure effectively. Low-income individuals are more stressed than those with higher incomes. Previous studies had shown that education could 
change individuals' acculturation orientations. In learning, individuals will learn mainstream cultural knowledge and contact mainstream cultural groups, which will more easily produce an open attitude towards acculturation. The acculturation difference of marriage is related to the traditional concept of Yi's marriage. In Yi society, Yi people can only choose to marry within their ethnic group for ethnic purity. They are not allowed to intermarry with other ethnic groups. As a result, married individuals, who learn and observe more traditional Yi customs, and whose partners are also $\mathrm{Yi}$, are more likely to interact with each other and develop negative mainstream cultural attitudes than unmarried individuals.

Statistics on ethnic identity showed that the Yi villagers' ethnic identity was generally high and did not show significant individual differences. The ethnic identity had no significant influence on gender, age, income, education, job, and marital status. The results confirmed that ethnic identity is more stable than the acculturation orientation. Ethnic identity is formed in the individual's growth stage and will not change with age, education, and income in adulthood. It also explains the apparent difference between ethnic identity and acculturation: relatively stable ethnic identity and constantly changing acculturation orientation.

\section{Ethnic Identity Has No Significant Influence on Mainstream Acculturation Attitude}

Strong ethnic identity does not lead to negative or positive mainstream acculturation attitudes, which may be related to the deep-rooted traditional thoughts of Yi villagers. They generally have a strong sense of ethnic identity. Since childhood, influenced by the traditional family concept, they have a relatively positive understanding of their ethnic group and ethnic identity. Their ethnic identity is not easy to be changed, not easy to be affected by the mainstream culture. Most of them will not reject the mainstream culture, which is also a common phenomenon among ethnic minorities in China, related to China's diversified and integrated cultural environment.

\section{Social Media Can Adjust and Improve Cultural Adaptation}

Social media can positively predict the mainstream acculturation attitude and improve the acculturation ability of the Yi villagers. Social media's popularity enables them to quickly and conveniently acquire mainstream cultural knowledge and contact mainstream groups in the relatively closed Yi area, thus improving individuals' cultural inadaptation. The survey results showed that social media use is generally high in Yi areas, with most people using WeChat. Social media use is lower among those over 50 or in primary school education. Yi area is also lower than mixed area. Besides, social media can negatively regulate the relationship between ethnic identity and original acculturation attitude. Consistent with the hypothesis, this suggests that social media use will reduce the positive effect of ethnic identity on the original acculturation attitude.

\section{Suggestions for Improving Acculturation of Yi Villagers}

\section{Popularize Network Knowledge in Pure Yi Areas and Publicize Positive Social Media Applications.}

The villagers living in pure Yi areas, especially the Sichuan Yi, tend to separate because they have little contact with the mainstream groups. Therefore, it is necessary to focus on improving the mainstream acculturation attitude in the Yi area and enhance their ability to adapt to mainstream culture. Studies have shown that villagers who use more social media have significantly higher acculturation abilities than those who less use social media. In today's 
information age, social media has been widely used in some ethnic minority areas. However, many Yi villages located in mountainous regions are still relatively closed, especially those who cannot read Chinese characters and who are older and do not know how to use the In ternet. The government and relevant departments should strengthen network knowledge in these areas, organize and carry out various community activities to learn and publicize network knowledge and social media applications. Make use of the country's digital currency policy to integrate into the digital community from passive acceptance actively. Simultaneously, all kinds of online groups, such as community groups, relatives, and friend groups, should be established to encourage villagers to communicate online, pay electricity bills online and deal with problems online.

\section{Social Support Should Be Emphasized to Enhance the Social Cohesion of Community Residents in Mixed Residential Areas}

Yi villagers in mixed areas live together with the mainstream groups, and some of them may face marginalization because of their inability to adapt to the mainstream culture and receive direct support from their ethnic. Research showed that social support could positively influence both ethnic identity and mainstream acculturation attitudes. Therefore, strengthening social support can effectively reduce the tendency of marginalization. The administrative departments should monitor and pay attention to the various effects of economic development on Yi society and further grasp intra-community relations' influence on residents' attitudes. They should actively explore the corresponding management mechanism, strengthen the benign and harmonious interaction between the community residents with the help of formal and informal organizations at all levels, increase the social capital stock of the community, enhance the residents' emotional connection and psychological identity to the community, maintain and build the interpersonal relationship of mutual trust and mutual support. The enhancement of community cohesion plays a vital role in improving the degree of acculturation of residents. The government and relevant departments need to strengthen social support to narrow the gap between individual acculturation in ideal and reality.

\section{Increase Investment in Primary and Secondary Education in Yi Region and Optimize Diversified Education Environment}

Primary and Secondary Education (PSE) is the leading education received by individuals in the growth stage, and the growth period is the crucial period for shaping individual values. Therefore, the PSE can help ethnic minority individuals establish correct cultural values and learn to live in harmony with mainstream groups in a multicultural environment. Current education pays more attention to mainstream society, often neglecting the PSE of ethnic minorities. Due to economic backwardness, there are many practical problems in the Yi area, such as poor PSE conditions, low salaries, and unstable teachers, so the PSE is far behind the mainstream society. It makes the minority teenagers at the cultural disadvantage easily feel inferior and maintain a solid defensive mentality towards the mainstream culture. Therefore, the government and related organizations need to increase support and input to solve Yi areas' PSE difficulties. These measures can enhance the local people's sense of cultural identity, improve the knowledge and ability of cross-cultural adaptation, and fundamentally promote Yi villagers' acculturation. Besides, multicultural education can improve the acculturation ability of community residents and the choice of adaptation strategies. Multicultural education and bilingual teaching in Yi villages and townships can enhance villagers' self-esteem, strengthen their sense of cultural identity, reduce their defensiveness and cultivate a sense of coexistence in a multicultural context. 


\section{Vigorously Develop the Economy and Improve the Income Level of Yi Villagers}

The study showed that the acculturation orientation of the Yi villagers is significantly related to income, and the acculturation ability of individuals with high income is significantly higher than that of individuals with low income. The Yi villagers live in the mountains, often have inconvenient transportation and backward economy. A lot of Yi village is still at poverty levels. Therefore, the government should continue strengthening the poverty alleviation work in the Yi area and implementing the current ethnic preferential policies. They should continue to increase the economic development and investment in ethnic regions, improve the Yi people's living standards, narrow the gap between urban and rural areas to promote their positive acculturation better.

\section{Conclusions and Limitations}

This study explored ethnic identity, social media, social support, and demographic variables on Yi villagers' acculturation orientations from different Yi areas. So far, there have been no other similar reports on Yi villagers' acculturation. This study showed that in the process of the interaction and collision between the traditional culture and the dominant culture, the traditional culture is constantly experiencing the conflict and fusion of "local tradition" and "modern development." The Yi people, who come from different backgrounds, have transformed from primitive to modern society, and their acculturation orientation has also experienced separation to integration. The Yi villagers' acculturation orientation is in line with Berry's Acculturation Model. The results also showed that the individual differences of Yi villagers' acculturation orientation are significant.

In contrast, the individual differences of ethnic identity are not significant, confirming the difference between ethnic identity and acculturation orientation. The regression analysis results confirmed most assumptions about the effects of social media and social support on the two attitudes towards acculturation. However, different from the hypothesis, ethnic identity did not influence the mainstream acculturation attitude. It may be related to the traditional thinking of the Yi villagers and their positive ethnic identity.

The study on the ethnic identity and acculturation of Yi people in the new period will help the government strengthen social governance in the $\mathrm{Yi}$ area and improve their acculturation ability. This paper put forward several suggestions to reduce cultural inadaptation. The government and relevant departments should carry out targeted work according to the characteristics of different Yi areas. They should speed up the economic development and improve the living standards. At the same time, it is necessary to develop the cultural and educational undertakings in the Yi region, to promote their positive ethnic identity and acculturation better.

Nevertheless, this study has some limitations. First, the sample in this study, although representative, is limited to the adjacent region. The limitation of the sample will affect the general applicability of the research results. It is not clear whether the patterns found in this study apply to the Yi villagers in other different regions or individuals in other contexts. Future work should attempt to obtain samples from other regions with different contexts, such as the Yi people from Guizhou and Guangxi province, better to examine the invariance or variability of the research results.

Secondly, most of the data in this study are from cross-section data. Although the data came from the same sample group, the analysis results also showed that the data used did not have significant homologous variance, but the data collected at a time node may deviate from the analysis results. A longitudinal approach could be used in future studies to examine the causal relationship between related variables further. Besides, the process of acculturation 
includes the orientation of acculturation and the results of acculturation. This paper measured and analyzed the attitude of acculturation, and the following research will consider the correlation between the results of acculturation and its precursors.

\section{Acknowledgment}

The authors wish to thank Han $\mathrm{Li}$, a professor of cross-cultural psychology, for his help in compiling the questionnaire and provided with a lot of his first-hand research materials. Thanks to the Yi students of Panzhihua University for their help in the survey.

\section{References}

Ai, A. L., Aisenberg, E., Weiss, S. I., \& Salazar, D. (2014). Racial/ethnic identity and subjective physical and mental health of Latino Americans: An asset within? American Journal of Community Psychology, 53(1-2), 173-184. https://doi.org/10.1007/s10464-014-9635-5

Argyris Y. E., \& Xu J. (2016). Enhancing self-efficacy for career development in Facebook. Computers in Human Behavior, 55, 921-931. https://doi.org/10.1016/j.chb.2015.10.023

Berry, J. W., \& Annis, R. C. (1974). Acculturative stress: The role of ecology, culture and differentiation. Journal of Cross-cultural Psychology, 5, 382-406. https://doi.org/10.1177/002202217400500402

Berry, J. W., \& Hou, F. (2019). Multiple belongings and psychological well-being among immigrants an the second generation in Canada. Canadian Journal of Behavioural Science-Revue Canadienne Des Sciences Du Comportement, 51(3), 159-170. https://doi.org/10.1037/cbs0000130

Berry, J. W., \& Sabatier, C. (2010). Acculturation, discrimination, and adaptation among the second generation of immigrant youth in Montreal and Paris. Interethnic Journal of Intercultural Relations, 34(3), 191-207. https://doi.org/10.1016 / j.i jintrel. 2009.11.007

Bulut, E., \& Gayman, M. D. (2020). A latent class analysis of acculturation and depressive symptoms among Latino immigrants: Examining the role of social support. International Journal of Intercultural Relations, 76, 13-25. https://doi.org/10.1016/j.ijintrel.2020.02.002

Cavdar, D., McKeown, S., \& Rose, J. (2021). Mental health outcomes of ethnic identity and acculturation among British-born children of immigrants from Turkey. New Directions for Child \& Adolescent Development, 2021(176), 141-161. https://doi.org/10.1002/cad.20402

Chung, N., \& Koo, C. (2015). The use of social media in travel information search. Telematics \& Iformatics, 32, 215-229. https://doi.org/10.1016/j.tele.2014.08.005

Compton, R. W., Leung, H. H., Robles, Y., \& ProQuest (Firm). (2018). Dynamics of community formation: Developing identity and notions of home. Palgrave Macmillan. https://doi.org/10.1057/978-1-137-53359-3

Douglass, S., \& Umaña-Taylor, A. J. (2016). Time-varying effects of family ethnic socialization on ethnic-racial identity development among Latino adolescents. Developmental Psychology, 52, 1904-1912. https://doi.org/10.1037/dev0000141

Ellison, N. B., Steinfield, C., \& Lampe, C. (2007). The benefits of Facebook "friends:" Social capital and college students' use of online social network sites. Journal of ComputeMediated Communication, 12(4), 1143-1168. https://doi.org/10.1111/j.10836101.2007.00367.x

Gilbreath, B., Kim, T. Y., \& Nichols, B. (2011). Person-environment fit and its effects on university students: A response surface methodology study. Research in Higher Education, 52, 47-62. https://doi.org/10.1007/s11162-010-9182-3 
Groenewold, G., \& de Valk Helga, A. G. (2017). Acculturation style, transnational behavior, and return-migration intentions of the Turkish second generation: Exploring linkages. Demographic Research, 37, 1707-1734. https://doi.org/10.4054/DemRes.2017.37.53

Han, L., Berry, J. W., \& Zheng, Y. (2016). The relationship of acculturation strategies to resilience: The moderating impact of social support among Qiang ethnicity following the 2008 Chinese earthquake. PloS one, 11(10). https://doi.org/10.1371/journal.pone.0164484

Haugen, I., \& Kunst, J. R. (2017). A two-way process? A qualitative and quantitative investigation of majority members' acculturation. International Journal of Intercultural Relations, 60, 67-82. https://doi.org/10.1016/j.ijintrel.2017.07.004

Hjellset, V. T., \& Ihlebæk, C. (2019). Bidimensional acculturation and psychological distress in Pakistani immigrant women in Norway: A cross-sectional study. Journal of Immigrant \& Minority Health, 21, 508-514. https://doi.org/10.1007/s10903-018-0764$\mathrm{Z}$

Hsiao, J., \& Wittig, M. (2008). Acculturation among three racial/ ethnic groups of host immigrant adolescents. American Journal of Community Psychology, 43, 286-297. https://doi.org/10.1007/s10464-008-9205-9

Kirschner, P. A., \& Karpinski, A. C. (2010). Facebook and academic performance. Computers in Human Behavior, 26, 1237-1245. https://doi.org/10.1016/j.chb.2010.03.024

Lardier Jr, D. T., Garcia-Reid, P., \& Reid, R. J. (2018). The interacting effects of psychological empowerment and ethnic identity on indicators of well-being among youth of color. Journal of Community Psychology, 46(4), 489-501. https://doi.org/10.1002/jcop.21953

Li, C., \& Tsai, W. H. S. (2015). Social media usage and acculturation: A test with Hispanics in the U.S. Computers in Human Behavior, 45, 204-212. https://doi.org/10.1016/j.chb.2014.12.018

Liu Ting. (2020). Research on the reconstruction of tourism space and the acculturation of traditional villages -- A case study of Baihualing Village, Nujiang Prefecture, Yunnan $\begin{array}{llll}\text { Province. Guizhou } & \text { Ethnic }\end{array}$ https://doi.org/10.13965/j.cnki.gzmzyj10026959.2020.09.007

Liu Xing. (2019). Adaptation and creation: On the inheritance path of Yi culture in Liangshan, Sichuan Province. Guizhou Ethnic Studies, 40(10), 100-105. https://doi.org/10.13965/j.cnki.gzmzyj10026959.2019.10.014

Mesoudi, A. (2018). Migration, acculturation, and the maintenance of between-group cultural variation. PLoS ONE, 13, e0205573. https://doi.org/10.1371/journal.pone.0205573

Miller, R., \& Melton, J. (2015). College students and risk-taking behaviour on Twitter versus Facebook. Behaviour \& Information Technology, 34(7). https://doi.org/10.1080/0144929X.2014.1003325

Mitra, A., \& Evansluong, Q. (2019). Narratives of integration: Liminality in migrant acculturation through social media. Technological Forecasting \& Social Change, 145, 474-480. https:doi.org/10.1016/j.techfore.2019.01.011

Pan Yu, \& Liu Shengzhi. (2019). The impact of social media on ethnic minority teenagers' ethnic identity. Contemporary Youth Studies, (03), 51-56. https://doi.10.3969/j.issn.1006-1789.2019.03.008

Pang, H., \& Wang, J. (2020). Promoting or prohibiting: Understanding the influence of social media on international students' acculturation process, coping strategies, and psychological consequences. Telematics \& Informatics, 54. https://doi.org/10.1016/j.tele.2020.101454

Phinney, J. S. (1992). The multigroup ethnic identity measure. Journal of Adolescent Research, 7(2), 156-176. https://doi.org/10.1177/074355489272003 
Phinney, J. S., \& Ong, A. D. (2007). Conceptualization and measurement of ethnic identity: Current status and future directions. Journal Of Counseling Psychology, 54(3), 271-281. https://doi.org/10.1037/0022-0167.54.3.271

Phinney, J. S., Horenczyk, G., Liebkind, K., \& Vedder, P. (2001). Ethnic identity, immigration, and well-being: An interactional perspective. Journal of Social Issues, 57(3), 493-510. https://doi.org/10.1111/0022-4537.00225

Purgason, L. L., Villalba, J. A., \& Fosback, C. (2020). Exploring ethnic identity through social networking sites: AQ methodology study with immigrant-origin college students. Journal of College Student Development, 61(2), 207-224. https://doi.org/10.1353/csd.2020.0018

Smith R. A., \& Khawaja, N. G. (2011). A review of the acculturation experiences of international students. International Journal of Intercultural Relations, 35(6), 699-713. https://doi.org/10.1016/j.ijintrel.2011.08.004

Verkuyten, M. (2018). The social psychology of ethnic identity (2nd ed.). Routledge. https://doi.org/10.4324/9781315109527

Vinokurov, A., Trickett, E. J., \& Birman, D. (2020). The effect of ethnic community on acculturation and cultural adaptation: The case of Russian-speaking older adults. Journal of International Migration \& Integration, 21(4), 1057-1081. https://doi.org/10.1007/s12134-019-00698-5

Ward, C., Stuart, J., \& Kus, L. (2011). The construction and validation of a measure of ethnocultural identity conflict. Journal of Personality Assessment, 93(5), 462-473. https://doi.org/10.1080/00223891.2011.558872

Xiao Zilun, Zheng Yingcan, LI Shuhui, Lu Jian, \& Chen Hong. (2018). Influence of Jia Zhi identity on the happiness of Yi college students: The moderating effect of ethnic identity. Psychological Science, 41(01), 138-144. https://doi.org/10.16719/j.cnki.16716981.20180121

Zhang Jing-ling, \& Zhang Qing-lin. (2007). The relationship between cultural identity and acculturation of ethnic minorities. Tissue engineering research \& Clinical Rehabilitation in China, (52), 10636-10639. https://doi.10.3321/j.issn:16738225.2007.52.070

Zhao Dan.(2018). Research on the guidance of social media on ethnic minority college students' Chinese cultural identity. National Journal, (03), 84-89+126-128. https://doi.10.3969/j.issn.1674-9391.2018.03.011

Zimet, G. D., Dahlem, N. W., Zimet, S. G., \& Farley, G. K. (1988). The multidimensional scale of perceived social support. Journal of Personality Assessment, 52(1), 30-41. https://doi.org/10.1207/s15327752jpa5201_2

\section{Notes on Contributors}

Yuan Shuangyun is a Ph.D student in Rattanakosin International College of Creative Entrepreneurship at Rajamangala University of Technology Rattanakosin in Thailand. She is an assistant researcher of Panzhihua University. Her research interests focus on mutual acculturation of ethnic minorities and majorities, multiple identities, ethnic identity, and intergenerational transmission of values and traditional culture in the information society.

Li Hongxia is a doctoral supervisor at Rajamangala University of Technology Rattanakosin in Thailand and a professor of Chongqing Technology and Business University in China. Her research interests focus on information management, management psychology and behavior, management science, operation management, information system, and information security. 